\title{
Stable Continuous Operation of a Biphasic Enantioselective Enzymatic Reduction
}

\author{
Pia Müller ${ }^{1}$, Benjamin L. Bangasser ${ }^{1}$, Lasse Greiner ${ }^{*}, 1,2$, Shukralla Na'amnieh ${ }^{3}$, Patrick S. Bäuerlein ${ }^{4}$, \\ Dieter Vogt ${ }^{4}$ and Christian Müller ${ }^{4}$
}

${ }^{I}$ ITMC, RWTH Aachen University, Worringerweg 1, Aachen, Germany

${ }^{2}$ DECHEMA e. V. Karl-Winnacker-Institut, Frankfurt am Main, Germany

${ }^{3} X$-Zyme GmbH, Düsseldorf, Germany

${ }^{4}$ Eindhoven University of Technology, Schuit Institute of Catalysis, Eindhoven, The Netherlands

\begin{abstract}
Continuous operation of alcohol dehydrogenase (ADH) catalysed enantioselective reduction in a biphasic sytem showed gains in productivity and stability of the overall reaction system. The total turnover numbers obtained for the cofactor $\mathrm{NADP}^{+}$are high with up to $1.5 \times 10^{4}$. Productivity for $(R)$-2-butanol with Lactobacillus brevis ADH was up to $26 \mathrm{kmol}(\mathrm{mol} \text { enzyme })^{-1}$. Enantioselectivity was greater than 0.99 for $(R)$-phenylethanol and up to 0.99 for $(R)$-butanol.
\end{abstract}

Keywords: Biocatalysis, continuous biphasic synthesis, enantioselective reduction, alcohol dehydrogenase from Lactobacillus brevis.

Alcohol dehydrogenases (ADH) are versatile catalysts for the enantioselective reduction of prochiral ketones to chiral alcohols. However, their applicability is mainly limited to aqueous buffers as the reactive phase. This is implied not only by the enzymes themselves but also by the insolubility of the required redox cofactors NADH or NADPH. Water as the only available reactive solvent limits productivity by solubility for a broad range of substrates. Using biphasic reaction systems with a non-reactive phase as a reservoir for substrates and products opened up both the use of sparingly water soluble substrates as well as expanding the thermodynamic boundaries of conversion limited systems $[1,2]$.

Specifically, the ADH from Lactobacillus brevis ( $L b A D H, \mathrm{NADP}^{+}$dependent) has been applied under biphasic conditions [3]. Apart from the common model substrate acetophenone our interest is in the production of enantiomerically enriched short chain alcohols. In these reactions enzymes are unmatched in enantioselectivity compared to chemical homogeneous catalysts. The most challenging substrate is butanone where to the best of our knowledge the best results for hydrogenation yielded enantiomeric excess ee $=0.72$ (enantiomeric ratio er $=6$ ) utilising Ru based catalysts, so far [4-6].

As non-reactive phase we evaluated methyl tert-butyl ether (2-methoxy-2-methyl-propane, MTBE) and the ionic liquid (IL) [N-pentyl N'-methyl imidazolium] hexafluorophosphate ([PMIM] $\mathrm{PF}_{6}$ ) [7-12] Commonly, the partition coefficients $p$ are near unity for both acetone and 2-propanol $[1,13,14]$. [PMIM] $\mathrm{PF}_{6}$ was chosen after screening of non-

*Address correspondence to this author at the DECHEMA e. V. KarlWinnacker-Institut, Frankfurt am Main, Germany; Tel: +49 6975640; Fax: +49 24180626484; E-mail: greiner@dechema.de water miscible IL as it shows full miscibility with acetone as the product of substrate coupled cofactor regeneration but not with the reducing agent 2-propanol. Thus, a favourable shift of equilibrium conversion towards the products should result. In practice, better conversion and enantioselectivity for batch reactions using MTBE were obtained with comparable selectivity (Table 1). This can be attributed to the non-ideal, i.e. concentration dependent, partitioning in the multi-component, non-diluted system (data not shown). In addition, traces of $\mathrm{HF}$ in the IL cannot be ruled out as a reason. Hydrolysis of $\mathrm{PF}_{6}$ can occur [15].

Table 1. Enantiomeric Excess (ee) and Conversion for the Substrate Coupled Reduction of Butanone to $(R)-2$ Butanol (Initial NADP ${ }^{+}$Concentration $0.1 \mathrm{mmol} \mathrm{L}^{-1}$ )

\begin{tabular}{|c|c|c|c|c|c|}
\hline Entry & $\begin{array}{c}\text { [Butanone] } \\
/ \mathbf{m m o l ~ L}^{-1}\end{array}$ & $\begin{array}{c}\text { [2-Propanol] } \\
\text { / } \mathrm{mol} \mathrm{L}^{-1}\end{array}$ & $\begin{array}{c}\text { Conversion }^{a} \\
/-\end{array}$ & $\begin{array}{c}e e^{a} \\
/-\end{array}$ & $\begin{array}{l}\text { Non-Reactive } \\
\text { Phase }\end{array}$ \\
\hline 1 & 20 & 0.2 & 0.31 & 0.92 & MTBE \\
\hline 2 & 20 & 2.0 & 0.32 & 0.96 & \\
\hline 3 & 50 & 0.2 & 0.19 & 0.90 & \\
\hline 4 & 50 & 2.0 & 0.46 & 0.98 & \\
\hline 5 & 100 & 0.2 & 0.22 & 0.70 & \\
\hline 6 & 100 & 2.0 & 0.33 & 0.91 & \\
\hline 7 & 20 & 0.2 & 0.08 & 0.99 & {$[\mathrm{PMIM}] \mathrm{PF}_{6}$} \\
\hline 8 & 20 & 2.0 & 0.12 & 0.99 & \\
\hline 9 & 50 & 0.2 & 0.07 & 0.65 & \\
\hline 10 & 50 & 2.0 & 0.15 & 0.96 & \\
\hline 11 & 100 & 0.2 & 0.04 & 0.97 & \\
\hline 12 & 100 & 2.0 & 0.34 & 0.76 & \\
\hline
\end{tabular}


To allow assessment of the regeneration method for the nicotine amide cofactors NADPH or $\mathrm{NADP}^{+}$in biphasic conditions, batch reactions were carried out utilising substrate coupled and enzyme coupled regeneration methods. Surprisingly, the regeneration method had a large impact on selectivity. The use of malate dehydrogenase (MDH) with $L-$ malic acid as the reducing agent and with MTBE as the nonreactive phase showed only moderate ee with less than 0.70 $(e r=5.5)$ (Table 2). Furthermore, enantioselectivity and conversion each showed a nonlinear correlation to the relative amounts of $\mathrm{LbADH}$ and $\mathrm{MDH}$. For conversion a maximum of 0.40 was reached. Both conversion and ee maximum values were obtained at an $\mathrm{ADH}: \mathrm{MDH}$ ratio of 0.13 . Exceeding this ratio led to a decrease of conversion as well as ee.

However, the transfer hydrogenation using the substrate coupled approach with 2-propanol as the reducing agent allowed for ee of up to $0.98(e r=53)$ and conversion of up to 0.46 using MTBE as the non-reactive phase (Table 1). With the IL $e e$ of $0.99(e r=4370)$ and conversion of up to 0.15 were achieved. Besides ADH:MDH ratio the initial butanone and the initial 2-propanol concentration influence conversion and selectivity. At constant 2-propanol concentration higher butanone concentrations cause lower conversion. In contrast, at constant butanone concentration a higher 2-propanol concentration leads to better conversion. Selectivity generally decreases with increasing butanone concentration, but is positively influenced by increasing 2-propanol concentration.

Table 2. Enantiomeric Excess (ee) and Conversion for the Enzyme Coupled Reduction of Butanone to $(R)-2-$ Butanol (Initial NADP ${ }^{+}$Concentration $0.1 \mathrm{mmol} \mathrm{L}^{-1}$ ) Depending on the ADH:MDH Ratio (Non-Reactive Phase: MTBE)

\begin{tabular}{|ccccc|}
\hline Entry & ADH:MDH & $\begin{array}{c}\text { [Butanone] } \\
\text { / mol L } \mathbf{L}^{-1}\end{array}$ & $\begin{array}{c}\text { conversion }^{a} \\
/-\end{array}$ & $\begin{array}{c}\boldsymbol{e} e^{a} \\
/-\end{array}$ \\
\hline \hline 1 & 0.08 & 50 & 0.32 & 0.64 \\
2 & 0.10 & 50 & 0.38 & 0.66 \\
3 & 0.13 & 20 & 0.35 & 0.53 \\
4 & 0.13 & 50 & 0.41 & 0.69 \\
5 & 0.13 & 100 & 0.25 & 0.67 \\
6 & 0.17 & 50 & 0.40 & 0.62 \\
7 & 0.25 & 50 & 0.33 & 0.65 \\
8 & 0.50 & 50 & 0.17 & 0.50 \\
9 & 1.00 & 50 & 0.05 & 0.32 \\
\hline
\end{tabular}

${ }^{a}$ Conversion and $e e$ after $2 \mathrm{~h}$ reaction time.

To fully exploit the beneficial use of the biphasic system a continuous reaction was carried out. Using the miniaturised biphasic reactor (MBR) [16] the aqueous reactive phase saturated with MTBE was stationary and remained in the reactor. As the non-reactive phase water saturated MTBE was continuously added and withdrawn using one continuously operated piston pump (Micromechatronic Technologies MMT, Germany) (Fig. 1).

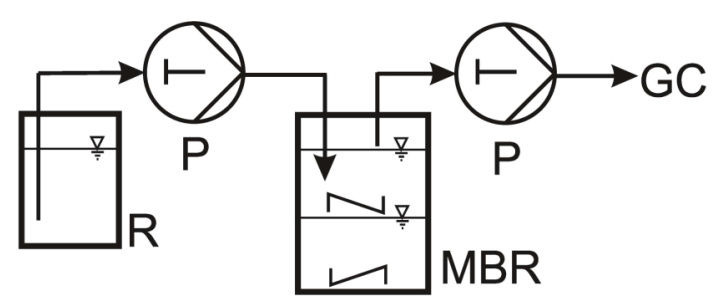

Fig. (1). Simplified flow scheme of the miniaturised biphasic reactor setup for the continuous enzymatic reduction (R: reservoir, P: piston pump, MBR: minaturised biphasic reactor, GC: online gas chromatography).

For comparison with previous results the reactor was first employed for the continuous reduction of acetophenone (AP) (Fig. 2). The reaction could be run for $140 \mathrm{~h}$ in total with high selectivity at rather low conversion averaging 0.10 . Nonetheless, a total turnover of the cofactor $\mathrm{NADP}^{+}$of 1900 far exceeds expectations from comparable batch experiments. After $120 \mathrm{~h}$ a decrease of conversion was apparent. Either deactivation of the $L b A D H$ under process conditions or deactivation of the nicotine amide cofactors are the most likely reasons.

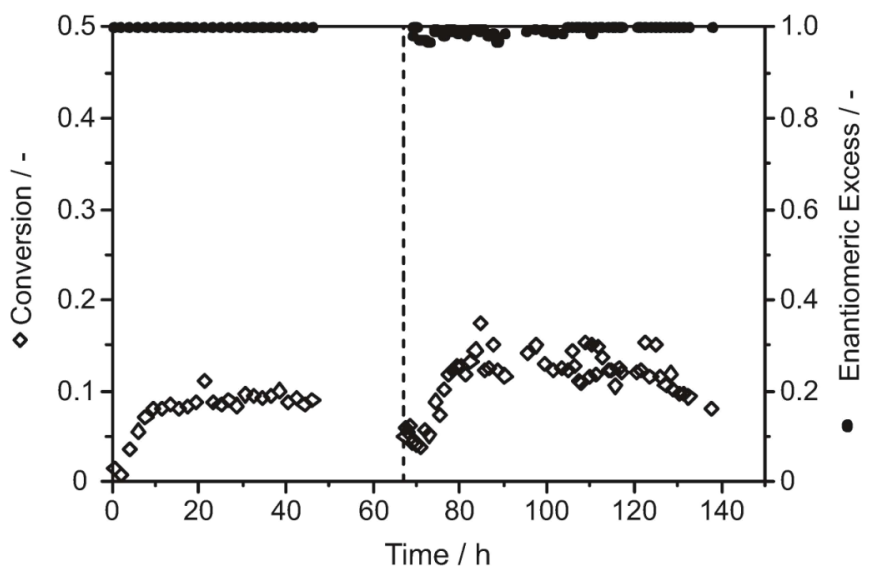

Fig. (2). Conversion and ee as a function of time for the continuous biphasic aqueous buffer/MTBE reduction of acetophenone to (R)-1phenylethanol (inlet: MTBE $[\mathrm{AP}]=50 \mathrm{mmol} \mathrm{L}^{-1},[2$-propanol] $=$ 2.0 mol L $\mathrm{L}^{-1}$; aqueous: $\mathrm{V}=5 \mathrm{~mL}, 5 \mathrm{mg} \mathrm{LbADH}$, potassium phosphate buffer $\mathrm{pH}=6.5,\left[\mathrm{NADP}^{+}\right]=0.1 \mathrm{mmol} \mathrm{L} \mathrm{L}^{-1}$; the perpendicular dashed line indicates change of residence time from 125 to $250 \mathrm{~min}$ ).

For the continuous reduction of the more challenging butanone a range of conditions were evaluated (Fig. 3). Initially, at 0.40 conversion $e e=0.95$ could be obtained at 85 min residence time. Increasing residence time by $40 \mathrm{~min}$ the maximum conversion was obtained at 0.58 giving a space time yield of $0.62 \mathrm{~g} \mathrm{~L}^{-1}$. Surprisingly, further increase of the residence time led to a slight decrease of conversion although the thermodynamically limiting conversion was estimated as 0.93 [2]. Apparently, ee decreases with time and is only slightly affected by residence time. The reasons for this are e.g. enzyme deactivation or cofactor availability which are currently under investigation. A total turnover number (TTN) for $\mathrm{NADP}^{+}$of 15400 was reached reflecting excellent cofactor and enzyme stability. In contrast, for the corresponding batch experiment (Table 1, entry 4) a TTN of 230 was obtained using MTBE. Assuming the protein in the technical preparation to be pure enzyme a productivity of

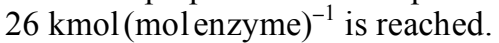




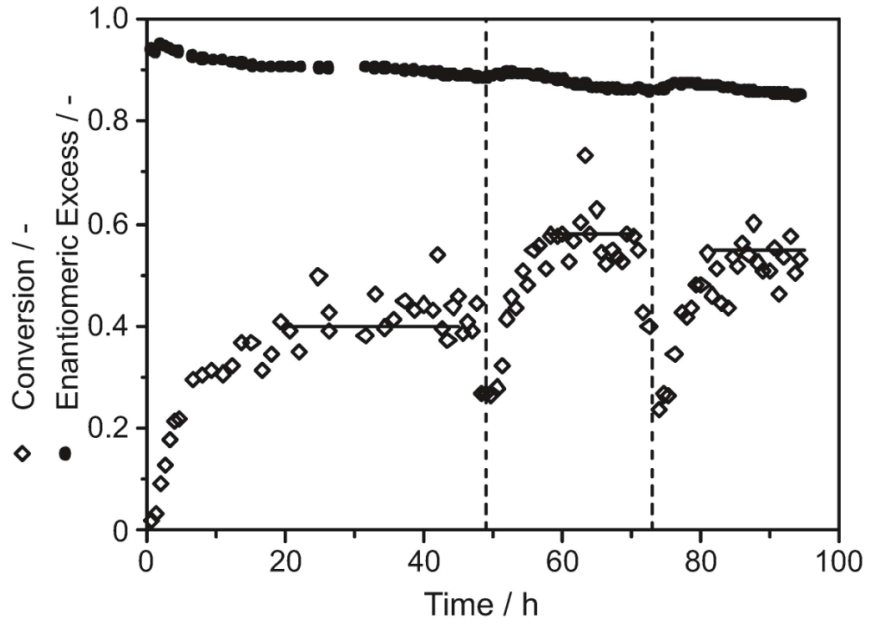

Fig. (3). Conversion and $e e$ as a function of time for the continuous biphasic aqueous buffer/MTBE reduction of butanone to (R)-2butanol (inlet: MTBE [butanone] $=50 \mathrm{mmol} \mathrm{L}^{-1}$, [2-propanol] $=2.0$ mol L ${ }^{-1}$; aqueous: $\mathrm{V}=5 \mathrm{~mL}, 5 \mathrm{mg} L b \mathrm{ADH}$, potassium phosphate buffer $\mathrm{pH}=7,\left[\mathrm{NADP}^{+}\right]=0.1 \mathrm{mmol} \mathrm{L}^{-1}$; the perpendicular dashed lines indicate changes of residence time from 85 to 125 to $156 \mathrm{~min}$ )

In conclusion continuous stable operation of the $\mathrm{LbADH}$ in the biphasic system aqueous buffer/MTBE was successfully demonstrated and outperforms the previously obtained results $[3,13,17,18]$. Both the high operational stability with no apparent loss of activity within $140 \mathrm{~h}$ of operation of the catalytic system of $\mathrm{LbADH}$ and the cofactor $\mathrm{NADP}^{+}$under these conditions are promising for further research and industrial applications. In the steady state, i.e. at constant conversion and ee, the MBR allows for a more detailed investigation of the factors which influence enzyme deactivation and limit conversion and selectivity. The batch experiments (Tables $\mathbf{1}$ and 2) have indicated that cofactor regeneration is the rate limiting step [19]. Therefore, the MBR is an appropriate tool to optimize the underlying reactions with respect to economic efficiency for industrial applications.

\section{MATERIALS AND METHODS}

\subsection{Batch Experiments}

Solutions of all reagents were always freshly prepared. The potassium phosphate buffer was used at a concentration of $50 \mathrm{mmol} \mathrm{L}{ }^{-1}$, its $\mathrm{pH}$ was set to 6.5 . Concentrations of butanone and 2-propanol are given in Tables $\mathbf{1}$ and 2. For the experiments using substrate coupled cofactor regeneration (Table 1) initial NADP ${ }^{+}$concentration was $0.1 \mathrm{mmol} \mathrm{L}^{-1}$, concentration of $L b A D H$ was $1.0 \mathrm{mg} \mathrm{mL} \mathrm{mL}^{-1}$. For the experiments using enzyme dependent cofactor regeneration the L-malic acid concentration was $60 \mathrm{mmol} \mathrm{L}^{-1}$ at an initial $\mathrm{NADP}^{+}$concentration of $0.1 \mathrm{mmol} \mathrm{L}{ }^{-1}$. ADH:MDH ratios are given in Table 2 . The reaction volume was $5 \mathrm{~mL}$ for all experiments. Samples of $50 \mu \mathrm{L}$ were taken at intermittent time intervals, mixed with $100 \mu \mathrm{L}$ of a $100 \mathrm{mmol} \mathrm{L}^{-1} 1$ butanol standard solution and analyzed via GC. Reaction solutions were stirred at $200 \mathrm{rpm}$.

\subsection{Continuous Experiments}

The MBR [16] has a total volume of $10 \mathrm{~mL}$. The reactive and the non-reactive phase are stirred independently, so the composition of each $5.0 \mathrm{~mL}$ phase is uniform. The phase boundary has to be preserved to allow for continuous removal of the MTBE phase. To avoid depletion of the aqueous phase due to continuous solution of water in the mobile organic phase, MTBE was saturated with water. To avoid initial adverse mixing processes the aqueous phase was presaturated with MTBE prior to the addition of $L b A D H$ and cofactor. Using a thermostat the reactor is constantly held at $30^{\circ} \mathrm{C}$. The substrate reservoir $\mathrm{R}$ contains the feed substrate solution which is substrate dissolved in water saturated MTBE (Fig. 1). A cryostat is employed to maintain it at $4.0^{\circ} \mathrm{C}$. A piston pump $\mathrm{P}$ feeds the substrate solution into the reactive phase of the reactor while it transfers the identical volume out of the reactor through the GC flow cell and into a the product reservoir. Thereby, the piston pump holds the volume of the mobile phase constantly at $5 \mathrm{~mL}$. At time intervals of $40 \mathrm{~min}$, the GC autosampler injects $1 \mu \mathrm{L}$ of a standard $100 \mathrm{mmol} \mathrm{L}^{-1} 1$-butanol solution, and $1 \mu \mathrm{L}$ of product solution from the flow cell. Sample and standard are injected together into the $\mathrm{GC}$ for analysis. The potassium phosphate buffer was used at a concentration of $50 \mathrm{mmol} \mathrm{L}^{-1}$, $\mathrm{pH}=6.5$. Concentrations of butanone and acetophenone were chosen as $50 \mathrm{mmol} \mathrm{L}^{-1}$ at a 2-propanol concentration of 2.0 $\mathrm{mol} \mathrm{L}^{-1}$. Initial NADP ${ }^{+}$concentration was $0.1 \mathrm{mmol} \mathrm{L}^{-1}$. The LbADH was used at a concentration of $5.0 \mathrm{mg} \mathrm{mL}$. Concentrations of butanone, acetophenone, and 2-propanol refer to a volume of $5 \mathrm{~mL}$ non-reactive phase, while concentrations of $\mathrm{NADP}^{+}$and $L b \mathrm{ADH}$ refer to a volume of 5 $\mathrm{mL}$ reactive phase.

\subsection{Gas Chromatography}

Continuous GC analysis was performed using an Agilent Technologies HP 6890 with a JAS-Unis Inlet. Column specifications: CP-Chirasil-DEX CB (Varian, $25 \mathrm{~m} \mathrm{x} 0.25$ $\mathrm{mm}$ inner diameter, film thickness $0.25 \mu \mathrm{m})$. As carrier gas $\mathrm{H}_{2}$ was used at a constant pressure of 0.5 bar. A temperature program was used as follows: initial temperature $40^{\circ} \mathrm{C}(3$ $\mathrm{min}), 1^{\circ} \mathrm{C} \min ^{-1}$ to $45^{\circ} \mathrm{C}(5 \mathrm{~min}), 10^{\circ} \mathrm{C} \min ^{-1}$ to $60^{\circ} \mathrm{C}(1$ $\mathrm{min})$. Retention times: butanone $2.7 \mathrm{~min},(R)$-2-butanol 6.6 min, $(S)$-2-butanol $6.9 \mathrm{~min}, 1$-butanol standard $11.8 \mathrm{~min}$.

\section{ACKNOWLEDGEMENTS}

Financial support by the German Federal Ministry of Economics and Technology (BMWi) via AiF (ZIM) and the Deutsche Forschungsgemeinschaft via the GRK 1166 BioNoCo are gratefully acknowledged. We thank Dr. Marrit Eckstein (RWTH Aachen University, now Evonik Degussa, Essen, Germany) and Dr. Christina Kohlmann (RWTH Aachen University, now Cognis, Düsseldorf, Germany) for discussion and advice.

\section{REFERENCES}

[1] Eckstein, M. F.; Peters, M.; Lembrecht, J.; Spiess, A. C., Greiner L. Maximise equilibrium conversion in biphasic catalysed reactions: mathematical description and practical guideline. $A d v$. Synth. Catal., 2006, 348, 1591-1596.

[2] Peters, M.; Eckstein,M. F.; Hartjen, G.; Spiess, A. C.; Leitner, W.; Greiner, L. Exploring conversion of biphasic catalytic reactions: analytical solution and parameter study. Ind. Eng. Chem. Res., 2007, 46, 7073-7078.

[3] Leuchs, S.; Greiner, L. Alcohol dehydrogenase from Lactobacillus brevis: A versatile catalyst for enenatioselective transformation. Chem. Biochem. Eng. Q., 2011, 25, 267-281.

[4] Huertas, R. E. ; Corella, J. A.; Soderquist, J. A. Asymmetric oxazaborolidine-catalyzed reduction of prochiral ketones with n- 
tert-butyl-n-trimethylsilylamine-borane. Tetrahedron Lett., 2003, 44, 4435-4437.

[5] Price, M. D.; Sui, J. K.; Kurth, M. J.; Schore, N. E. Oxazaborolidines as Functional Monomers: Ketone Reduction Using PolymerSupported Corey, Bakshi, and Shibata Catalysts. J. Org. Chem., 2002, 67, 8086 .

[6] Li, X; Wu, X.; Chen, W.; Hancock, F. E.; King, F.; Xiao. Asymmetric transfer hydrogenation in water with a supported noyori-ikariya catalyst. J. Org. Lett., 2004, 6, 3321.

[7] van Rantwijk, F.; Sheldon, R. A: Biocatalysis in ionic liquids. Chem. Rev., 2007, 107, 2757.

[8] Cantone, S.; Hanefeld, U.; Basso, A. Biocatalysis in nonconventional media - ionic liquids, supercritical fluids and the gas phase. Green Chem., 2007, 9, 954.

[9] Roosen, C.; Müller, P.; Greiner, L. Ionic liquids in biotechnology: applications and perspectives for biotransformations. Appl. Microbiol. Biot., 2008, 81, 607.

[10] Lozano, P. Enzymes in neoteric solvents: From one-phase to multiphase systems. Green Chem., 2010, 12, 555.

[11] Hernáiz, M. J.; Alcántara, A. R.;García, J. L.; Sinisterra, J. L. Applied biotransformations in green solvents. Chem-Eur. j., 2010, $16,9422$.

[12] Domínguez de Maria, P. "Nonsolvent" applications of ionic liquids in biotransformations and organocatalysis. Angew. Chem. Int. Edit., 2008, 47, 6960.

[13] Eckstein, M. F.; Villela Filho, M.; Liese, A.; Kragl, U. Use of an ionic liquid in a two-phase system to improve an alcohol dehydrogenase catalysed reduction. Chem. Commun., 2004, 10841085.

[14] Eckstein, M. F.; Lembrecht, J.; Schumacher, J.; Eberhard, W.; Spiess, A. C.; Peters, M.; Roosen, C.; Greiner, L.; Kragl, U. Maximise equilibrium conversion in biphasic catalysed reactions: How to obtain reliable data for equilibrium constants. Adv. Synth. Catal., 2006, 348, 1597-1604.

[15] Holbrey, J. D.; Reichert, M.; Swatlowski, R. P.; Broker, G. A.; Pitner, W. R.; Seddon, K. R.; Rogers, R. D. Efficient, halide free synthesis of new, low cost ionic liquids: 1,3-dialkylimidazolium salts containing methyl and ethyl-sulfate anions. Green Chem., $\mathbf{2 0 0 3}, 4,407-413$.

[16] van den Wittenboer, A.; Schmidt, T. W.; Müller, P.; AnsorgeSchumacher, M. B.; Greiner, L. Biphasic mini-reactor for characterization of biocatalyst performance. Biotech. J., 2009, 4, 44-50.

[17] Villela Filho, M.; Stillger, T.; Müller, M.; Liese, A.; Wandrey, C. Is $\log \mathrm{P}$ a convenient criterion to guide the choice of solvents for biphasic enzymatic reactions? Angew. Chem. Int. Edit., 2003, 115, 3101-3104.

[18] Gröger, H.; Hummel, W.; Buchholz, S.; Drauz, K.-H.; Van Nguyen, T.; Rollmann, C.; Hüsken, H.; Abokitse, K. Practical asymmetric enzymatic reduction through discovery of a dehydrogenase-compatible biphasic media. Org. Lett. 2002, 5, 173.

[19] Schumacher, J.; Eckstein, M.; Kragl, U. Influence of watermiscible organic solvents on kinetics and enantioselectivity of the $(R)$-specific alcohol dehydrogenase from Lactobacillus brevis. Biotech. J., 2006, 1, 574.

(C) Müller et al.; Licensee Bentham Open.

This is an open access article licensed under the terms of the Creative Commons Attribution Non-Commercial License (http://creativecommons.org/licenses/by-nc/ 3.0/) which permits unrestricted, non-commercial use, distribution and reproduction in any medium, provided the work is properly cited. 